\title{
AVALIAÇÃO DO TEOR DE COBRE E ZINCO EM CARNES CRUAS, PROCESSADAS TERMICAMENTE, RESFRIADAS E CONGELADAS NO PERÍODO DE UM MÊS
}

\author{
Édira Castello Branco de ANDRADE ${ }^{2 *}$, Aline Mota BARROS ${ }^{2}$,
}

\author{
Vanessa de Souza MELLO², Iracema TAKASE ${ }^{3}$
}

\section{RESUMO}

Para que elementos químicos, como o cobre e o zinco, sejam utilizados pelos sistemas biológicos, é necessário que estejam disponíveis para absorção, sendo assim, apenas a sua abundância na natureza não é fator que garanta a sua absorção. As carnes bovinas e de aves são de grande importância na alimentação, justamente por serem alimentos fonte de proteínas de alto valor biológico e lipídios. Processos de conservação através de refrigeração e congelamento, bem como processamento térmico, podem alterar fisicamente as carnes. Este trabalho tem como objetivo avaliar o comportamento de cobre e zinco em carnes resfriadas e conservadas em temperatura de congelamento por um período de 1 mês, processadas termicamente e in natura. Os teores de cobre e zinco foram determinados através da espectroscopia de absorção atômica. Os dados foram tratados estatisticamente através do teste de Grubs e t de Student. Mesmo com perdas no processamento térmico, e com a conservação em temperatura de congelamento durante o período de 4 semanas, o teor de cobre na maioria das amostras estudadas foi superior a $0,025 \mathrm{mg} \%$, e o do zinco superior a $0,3 \mathrm{mg} \%$ para as amostras de carnes de aves e $0,6 \mathrm{mg} \%$ para as amostras de carnes bovinas.

Palavras-chave: cobre; zinco; processamento térmico; congelamento; carnes.

\section{SUMMARY}

EVALUATION OF COPPER AND ZINC IN MEATS THERMALLY PROCESSED AND CONSERVATED IN FREEZER FOR A MONTH Copper and zinc can appear in nature under chemical forms, the solubility of theses metals can be determinated bio-availability.Meats from cattle or chicken are sources of proteins and lipids wich are very important for human nutrition. Thermal processing as cooking, refrigeration and freezing can modifie fisical and chemical structures of meats tissues.Samples of meat from cattle and chicken, in two batches of each variety, were thermally processed and conservated in freezer for a month, and the total ratio of copper and zinc was determined through flame atomic absorption spectroscopy. Both the Grubs and t test by Student were used for the analysis. It was observed that, after freezing and thermal processing copper and zinc were lost but the amount of these metals were more than $0.025 \mathrm{mg} \%$ for copper in almost all samples and $0.3 \mathrm{mg} \%$ of zinc for chicken meats and $0.6 \mathrm{mg} \%$ for cattle meats.

Keywords: copper; zinc; thermal processing; freezing; meats.

\section{1 - INTRODUÇÃO}

O organismo humano é constituído de vários elementos químicos que compõem os macronutrientes, os micronutrientes e os elementos traço $[1,4,6,8,10,11$, $14,16,18]$.

O cobre e o zinco são elementos traço e participam de várias reações no organismo, diretamente ou como co-fator de enzimas. Sinais e sintomas clínicos são apresentados, caso haja deficiência ou toxicidade destes elementos $[4,8,10,14,16,18]$.

Apesar dos dados não serem suficientes para estabelecer uma recomendação diária ideal desses oligoelementos, segundo as DRIs (Dietary Reference Intakes) para o cobre a recomendação é de 1,0 a $1,6 \mathrm{mg} /$ dia, tolerável $10 \mathrm{mg} /$ dia e para o zinco de 9 a $14 \mathrm{mg} /$ dia, tolerável $40 \mathrm{mg} /$ dia para adultos. [7, 9]

\footnotetext{
Recebido para publicação em 10/02/2003. Aceito para publicação em 06/07/2004 (001069).

2. Universidade do Estado do Rio de Janeiro - Escola de Nutrição Departamento de Tecnologia dos Alimentos - Rua Xavier Sigaud no 290 predio II, $3^{\circ}$ andar, Urca, Rio de Janeiro-RJ, CEP: 20211-040. E-mail: ediracba@unirio.br

3. Universidade Federal do Rio de Janeiro - Faculdade de Química Departamento de Química Analítica

* A quem a correspondência deve ser enviada.
}

Para que elementos químicos, como o cobre e o zinco, sejam utilizados pelos sistemas biológicos, é necessário que estejam disponiveis para absorção. Sendo assim apenas a sua abundância na natureza não é fator que garanta a sua absorção. Esta disponibilidade é influenciada por vários fatores como: capacidade de solubilização das espécies dos elementos, pela possibilidade de ionização dos compostos solúveis, pela formação de complexos e pelas condições de prevalência dos diferentes estados de oxidação dos elementos na região da estabilidade da água $[6,8,10,17,18]$.

As carnes bovinas e de aves são de grande importância na alimentação, justamente por serem alimentos fonte de proteínas de alto valor biológico e de lipídios. As carnes de um modo geral são alimentos fonte de várias vitaminas lipossolúveis, assim como de elementos traço, tal como o zinco [2, 8].

Processos de conservação através de refrigeração e congelamento, bem como processamentos térmicos, podem alterar fisicamente as carnes promovendo alterações nos teores dos elementos traços. O processo de refrigeração utiliza temperaturas entre $-1^{\circ} \mathrm{C}$ e $10^{\circ} \mathrm{C}$. Este processo não possui ação esterilizante, apenas retarda as atividades microbianas já existentes e impede o surgimento de novos agentes deteriorantes. Apesar do método de refrigeração possibilitar a manutenção das qualidades nutritivas da carne, ele é menos eficaz quando se trata da manutenção dos caracteres sensoriais. O congelamento, por empregar temperaturas mais bai- 
xas que a refrigeração, prolonga o tempo de conservação da carne. As temperaturas utilizadas diminuem ou paralisam a deterioração causada por microrganismos, enzimas ou agentes químicos. Além disso, o congelamento é um dos melhores métodos para manter a cor, o aroma e a aparência do alimento [ $3,5,15]$.

Este trabalho tem como objetivo determinar os teores de cobre e zinco em carnes resfriadas e conservadas em temperatura de congelamento, por um período de 1 mês, processadas termicamente e in natura.

\section{2 - MATERIAIS E MÉTODOS}

\section{1 - Amostras}

As amostras analisadas foram: carne de frango (peito e coxa), carne bovina (lagarto, alcatra, chã e patinho). Cada amostra foi adquirida em dois locais distintos, tendo assim duas amostras para cada corte de carne, e foram feitas 5 sub-amostras de cada amostra na análise dos teores de cobre e zinco.

\section{2 - Tratamento de amostras}

Todas as amostras foram fracionadas e embaladas com filme de pvc em cinco porções. Uma porção, representando a amostra resfriada foi imediatamente analisada. As outras porções foram conservadas em freezer nos tempos de 1 a 4 semanas. O descongelamento foi feito por doze horas em temperatura ambiente.

\section{3 - Processamento térmico}

As amostras foram processadas termicamente através de cocção convencional, em meio aquoso, utilizando panela de alumínio.

Digestão das amostras - a abertura das amostras, para a determinação do teor total de cobre e zinco, foi feita através da calcinação a $550^{\circ} \mathrm{C}$ por um período mínimo de 2 horas. As cinzas foram dissolvidas em $\mathrm{HCl}$ $2 \mathrm{molL}^{-1}$ e transferidas quantitativamente para balão volumétrico de $25 \mathrm{~mL}$.

\subsection{1 - Determinação do teor total de cobre e zinco}

O teor total de cobre e zinco nas amostras foi determinado através da espectroscopia de absorção atômica em chama.

\subsection{2 - Análise estatística}

Os resultados foram analisados, estatisticamente, através do teste de Grubs e do teste t de Student.

\subsection{3 - Garantia da qualidade}

Para a determinação dos teores de cobre e zinco nas amostras, o aparelho de absorção atômica foi sempre previamente calibrado com soluções analíticas dos respectivos metais. De cada amostra foram preparadas cinco calcinações, obtendo-se cinco soluções mantendo sempre as análises em quintuplicata.

\section{3 - RESULTADOS E DISCUSSÃO}

As Tabelas 1 e 2 apresentam os teores de cobre nas amostras in natura e após processamento térmico, respectivamente, resfriadas e conservadas em temperatura de congelamento por períodos de até 1 mês.

TABELA 1. Teor total de $\mathrm{Cu}$ em $\mu \mathrm{g} / \mathrm{g}$ de carnes in natura resfriadas e congeladas em diferentes períodos

\begin{tabular}{cccccc}
\hline \multirow{2}{*}{ Amostras } & \multirow{2}{*}{ Resfriada } & $\begin{array}{c}\text { Congelada } \\
\text { 1 semana }\end{array}$ & $\begin{array}{c}\text { Congelada } \\
\text { 2 semanas }\end{array}$ & $\begin{array}{c}\text { Congelada } \\
\text { 3 semanas }\end{array}$ & $\begin{array}{c}\text { Congelada } \\
\text { 4 semanas }\end{array}$ \\
\hline Peito de frango I & $0,48 \pm 0,03$ & $0,45 \pm 0,05$ & $0,38 \pm 0,01$ & $0,36 \pm 0,08$ & $0,31 \pm 0,03$ \\
Peito de frango II & $0,46 \pm 0,04$ & $0,42 \pm 0,07$ & $0,34 \pm 0,02$ & $0,34 \pm 0,03$ & $0,31 \pm 0,02$ \\
Coxa de frango I & $*$ & $*$ & $*$ & $*$ & $*$ \\
Coxa de Frango II & $*$ & $*$ & $*$ & $*$ & $*$ \\
Alcatra I & $0,77 \pm 0,08$ & $0,50 \pm 0,01$ & $0,46 \pm 0,01$ & $0,40 \pm 0,01$ & $0,37 \pm 0,02$ \\
Alcatra II & $0,72 \pm 0,05$ & $0,50 \pm 0,02$ & $0,46 \pm 0,01$ & $0,44 \pm 0,01$ & $0,38 \pm 0,04$ \\
Ch,, I & $0,76 \pm 0,02$ & $0,60 \pm 0,02$ & $0,51 \pm 0,02$ & $0,53 \pm 0,04$ & $0,48 \pm 0,03$ \\
Ch, II & $0,70 \pm 0,02$ & $0,56 \pm 0,07$ & $0,51 \pm 0,03$ & $0,48 \pm 0,02$ & $0,43 \pm 0,02$ \\
Lagarto I & $0,66 \pm 0,12$ & $0,50 \pm 0,01$ & $0,42 \pm 0,02$ & $0,42 \pm 0,02$ & $0,33 \pm 0,04$ \\
Lagarto II & $0,72 \pm 0,18$ & $0,54 \pm 0,03$ & $0,42 \pm 0,02$ & $0,41 \pm 0,01$ & $0,35 \pm 0,04$ \\
Patinho I & $0,55 \pm 0,03$ & $0,51 \pm 0,02$ & $0,52 \pm 0,03$ & $0,51 \pm 0,02$ & $0,48 \pm 0,01$ \\
Patinho II & $0,56 \pm 0,02$ & $0,53 \pm 0,01$ & $0,49 \pm 0,02$ & $0,51 \pm 0,02$ & $0,48 \pm 0,01$ \\
\hline - teor de Cu inferior a $0,1 \mu \mathrm{g} / \mathrm{g}$ & & & &
\end{tabular}

Analisando a Tabela 1, observa-se que as amostras resfriadas estudadas apresentam teores similares do cobre independente do local de compra. Verifica-se que as carnes do tipo bovina apresentam maior concentração deste metal quando comparadas com as carnes de aves. Observa-se que para todas as amostras estudadas a perda de cobre aumenta com o decorrer do tempo de congelamento. Para a maioria das amostras esta perda é superior a $35 \%$ do teor inicial de cobre a partir de 2 semanas de congelamento. As maiores perdas ocorrem nas amostras de carnes bovinas do tipo alcatra e lagarto. Interessante verificar que a carne bovina do tipo patinho apesar de ser a que tem menor teor de cobre, é a que apresenta menor perda durante o período de congelamento, não ultrapassando $15 \%$. Observa-se também que os outros tipos de corte bovino com suas perdas chegam ao teor de cobre similar ao encontrado no patinho.

TABELA 2. Teor de $\mathrm{Cu}(\mu \mathrm{g} / \mathrm{g}$ amostra crua) em carnes processadas termicamente resfriadas e congeladas em diferentes períodos

\begin{tabular}{cccccc}
\hline Amostras & Resfriada & $\begin{array}{c}\text { Congelada } \\
\text { 1 semana }\end{array}$ & $\begin{array}{c}\text { Congelada } \\
\text { 2 semanas }\end{array}$ & $\begin{array}{c}\text { Congelada } \\
\text { 3 semanas }\end{array}$ & $\begin{array}{c}\text { Congelada } \\
\text { 4 semanas }\end{array}$ \\
\hline Peito de frango I & $0,38 \pm 0,01$ & $0,31 \pm 0,03$ & $0,31 \pm 0,02$ & $0,34 \pm 0,01$ & $0,29 \pm 0,02$ \\
Peito de frango II & $0,32 \pm 0,01$ & $0,28 \pm 0,01$ & $0,29 \pm 0,03$ & $0,32 \pm 0,02$ & $0,28 \pm 0,02$ \\
Coxa de frango I & $*$ & $*$ & $*$ & $*$ & $*$ \\
Coxa de Frango II & $*$ & $*$ & $*$ & $*$ & $*$ \\
Alcatra I & $0,61 \pm 0,04$ & $0,34 \pm 0,01$ & $0,27 \pm 0,01$ & $0,27 \pm 0,03$ & $0,26 \pm 0,02$ \\
Alcatra II & $0,53 \pm 0,01$ & $0,34 \pm 0,01$ & $0,34 \pm 0,01$ & $0,30 \pm 0,01$ & $0,27 \pm 0,02$ \\
Ch, I & $0,35 \pm 0,03$ & $0,28 \pm 0,02$ & $0,30 \pm 0,02$ & $0,28 \pm 0,02$ & $0,25 \pm 0,01$ \\
Ch,, II & $0,31 \pm 0,05$ & $0,29 \pm 0,01$ & $0,29 \pm 0,02$ & $0,28 \pm 0,03$ & $0,26 \pm 0,03$ \\
Lagarto I & $0,46 \pm 0,03$ & $0,38 \pm 0,01$ & $0,29 \pm 0,01$ & $0,28 \pm 0,03$ & $0,26 \pm 0,04$ \\
Lagarto II & $0,43 \pm 0,02$ & $0,42 \pm 0,01$ & $0,27 \pm 0,01$ & $0,34 \pm 0,01$ & $0,29 \pm 0,04$ \\
Patinho I & $0,26 \pm 0,01$ & $0,27 \pm 0,02$ & $0,25 \pm 0,01$ & $0,25 \pm 0,01$ & $0,26 \pm 0,02$ \\
Patinho II & $0,26 \pm 0,01$ & $0,28 \pm 0,01$ & $0,26 \pm 0,02$ & $0,28 \pm 0,04$ & $0,25 \pm 0,02$ \\
\hline * teor de Cu inferior a $0,1 \mu \mathrm{g} / \mathrm{g}$ & & & &
\end{tabular}


Observando a Tabela 2, verifica-se que as perdas também aumentam com o decorrer do tempo de congelamento, mas esta perda não é tão significativa em comparação as amostras in natura. Para a maioria das amostras a perda foi menor e as amostras de carne bovina do tipo patinho não apresentaram perda significativa após tratamento dos dados estatisticamente com o uso do teste $\mathrm{t}$.

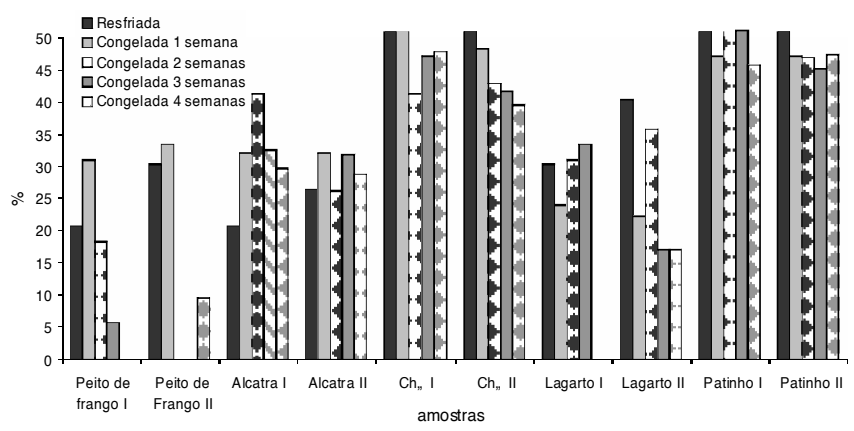

FIGURA 1. Teor \% de cobre perdido durante processo térmico de amostras de carnes resfriadas e congeladas até 4 semanas

A Figura 1 apresenta as perdas percentuais de cobre durante o processo térmico comparando as carnes in natura com as carnes cozidas em fogão convencional. Observa-se que as perdas para as carnes de aves diminuem com o decorrer do tempo de congelamento, sendo que para algumas amostras não houve perda significativa do cobre durante o processo de cocção após 2 semanas de congelamento. Para a maioria das carnes bovinas a conservação por congelamento não influenciou na perda de cobre durante o processo de cocção, mantendo teores similares às carnes in natura e cozidas.

As Tabelas 3 e 4 apresentam os teores de zinco nas amostras in natura e processadas termicamente, respectivamente, resfriadas e conservadas em temperatura de congelamento por períodos distintos.

TABELA 3. Teor total de $\mathrm{Zn}$ em $\mathrm{mg} \%$ em carnes in natura resfriadas e congeladas em diferentes períodos

\begin{tabular}{crrrrr}
\hline Amostras & Resfriada & $\begin{array}{c}\text { Congelada } \\
\text { 1 semana }\end{array}$ & $\begin{array}{c}\text { Congelada } \\
\text { 2 semanas }\end{array}$ & $\begin{array}{c}\text { Congelada } \\
\text { 3 semanas }\end{array}$ & $\begin{array}{c}\text { Congelada } \\
\text { 4 semanas }\end{array}$ \\
\hline Peito de frango I & $0,76 \pm 0,07$ & $0,71 \pm 0,07$ & $0,63 \pm 0,02$ & $0,40 \pm 0,02$ & $0,39 \pm 0,02$ \\
Peito de frango II & $0,76 \pm 0,09$ & $0,64 \pm 0,08$ & $0,60 \pm 0,06$ & $0,43 \pm 0,06$ & $0,41 \pm 0,07$ \\
Coxa de frango I & $1,76 \pm 0,04$ & $1,40 \pm 0,10$ & $1,39 \pm 0,03$ & $1,21 \pm 0,04$ & $1,24 \pm 0,17$ \\
Coxa de Frango II & $1,69 \pm 0,05$ & $1,33 \pm 0,04$ & $1,41 \pm 0,03$ & $1,21 \pm 0,06$ & $1,17 \pm 0,07$ \\
Alcatra I & $2,82 \pm 0,56$ & $2,82 \pm 0,49$ & $1,97 \pm 0,33$ & $1,13 \pm 0,19$ & $1,10 \pm 0,25$ \\
Alcatra II & $2,02 \pm 0,2$ & $1,69 \pm 0,16$ & $1,65 \pm 0,14$ & $1,11 \pm 0,27$ & $1,07 \pm 0,11$ \\
Ch, I & $3,84 \pm 0,08$ & $3,52 \pm 0,05$ & $3,33 \pm 0,04$ & $3,20 \pm 0,05$ & $3,20 \pm 0,06$ \\
Ch,, II & $3,98 \pm 0,08$ & $3,53 \pm 0,05$ & $3,23 \pm 0,06$ & $3,33 \pm 0,05$ & $3,24 \pm 0,05$ \\
Lagarto I & $2,90 \pm 0,07$ & $2,24 \pm 0,17$ & $1,21 \pm 0,09$ & $0,71 \pm 0,17$ & $0,73 \pm 0,04$ \\
Lagarto II & $3,65 \pm 0,14$ & $2,52 \pm 0,25$ & $1,46 \pm 0,39$ & $0,72 \pm 0,09$ & $0,70 \pm 0,05$ \\
Patinho I & $4,33 \pm 0,08$ & $3,91 \pm 0,26$ & $4,02 \pm 0,26$ & $3,77 \pm 0,26$ & $3,78 \pm 0,20$ \\
Patinho II & $4,05 \pm 0,24$ & $3,82 \pm 0,20$ & $3,70 \pm 0,30$ & $4,08 \pm 0,57$ & $3,69 \pm 0,47$ \\
\hline
\end{tabular}

Analisando a Tabela 3, é possível observar que a maioria das amostras apresenta teor similar de zinco independente do local de compra. Observa-se que a perda ocorre desde a primeira semana de congelamento tendo seu pico máximo em 3 semanas de congelamento em média $40 \%$. As carnes de aves (peito) e bovinas (alcatra e lagarto) apresentaram perda superior a $45 \%$ após 4 semanas de congelamento. A carne bovina do tipo lagarto foi a que apresentou maior perda de zinco acima de $7 \%$ e o patinho a de menor perda, inferior a $13 \%$.

Observando a Tabela 4 verifica-se que as perdas após o período de congelamento foram menores em comparação as amostras in natura. As amostras de carnes de aves (peito) e bovinas (alcatra e lagarto), apresentaram perda superior a $45 \%$, sendo que as amostras de lagarto tiveram perda em média de $70 \%$ do teor inicial de zinco. As amostras de carnes de ave (coxa) e bovinas (patinho e chã), apresentaram perda inferior a 20\% do teor inicial de zinco.

TABELA 4. Teor \% de $\mathrm{Zn}$ (mg/100g de amostra crua) em carnes processadas termicamente resfriadas e congeladas em diferentes períodos

\begin{tabular}{cccccc}
\hline Amostras & Resfriada & $\begin{array}{c}\text { Congelada } \\
1 \text { semana }\end{array}$ & $\begin{array}{c}\text { Congelada } \\
\text { 2 semanas }\end{array}$ & $\begin{array}{c}\text { Congelada } \\
\text { 3 semanas }\end{array}$ & $\begin{array}{c}\text { Congelada } \\
\text { 4 semanas }\end{array}$ \\
\hline Peito de frango I & $0,65 \pm 0,05$ & $0,58 \pm 0,07$ & $0,59 \pm 0,04$ & $0,36 \pm 0,03$ & $0,32 \pm 0,03$ \\
Peito de frango II & $0,57 \pm 0,04$ & $0,53 \pm 0,03$ & $0,51 \pm 0,04$ & $0,34 \pm 0,04$ & $0,3 \pm 0,05$ \\
Coxa de frango I & $0,91 \pm 0,05$ & $0,93 \pm 0,07$ & $0,79 \pm 0,07$ & $0,76 \pm 0,03$ & $0,8 \pm 0,04$ \\
Coxa de Frango II & $0,97 \pm 0,11$ & $0,94 \pm 0,03$ & $0,85 \pm 0,09$ & $0,76 \pm 0,04$ & $0,78 \pm 0,08$ \\
Alcatra I & $2,37 \pm 0,25$ & $1,95 \pm 0,11$ & $1,49 \pm 0,25$ & $1,05 \pm 0,09$ & $1,05 \pm 0,13$ \\
Alcatra II & $1,67 \pm 0,24$ & $1,78 \pm 0,18$ & $1,63 \pm 0,16$ & $0,96 \pm 0,27$ & $0,94 \pm 0,07$ \\
Ch,, I & $3,15 \pm 0,04$ & $2,9 \pm 0,06$ & $2,81 \pm 0,05$ & $2,79 \pm 0,16$ & $2,58 \pm 0,02$ \\
Ch,, II & $3,07 \pm 0,08$ & $2,69 \pm 0,17$ & $2,79 \pm 0,15$ & $2,67 \pm 0,03$ & $2,75 \pm 0,04$ \\
Lagarto I & $2,00 \pm 0,35$ & $1,76 \pm 0,23$ & $0,86 \pm 0,04$ & $0,88 \pm 0,08$ & $0,64 \pm 0,04$ \\
Lagarto II & $3,24 \pm 0,43$ & $1,92 \pm 0,27$ & $1,09 \pm 0,03$ & $0,66 \pm 0,08$ & $0,59 \pm 0,03$ \\
Patinho I & $3,17 \pm 0,20$ & $3,21 \pm 0,39$ & $3,28 \pm 0,35$ & $2,63 \pm 0,28$ & $2,89 \pm 0,14$ \\
Patinho II & $3,31 \pm 0,2$ & $3,11 \pm 0,20$ & $3,83 \pm 0,23$ & $2,97 \pm 0,34$ & $2,77 \pm 0,2$ \\
\hline
\end{tabular}

A Figura 2 apresenta as perdas percentuais de zinco durante o processo térmico comparando as carnes in natura com as carnes cozidas em fogão convencional. Observa-se que, para a maioria das amostras, a perda do zinco decresce com o decorrer do tempo de congelamento, sendo que para algumas amostras a perda se mantém similar, não havendo influência do período de conservação através do congelamento. Para a maioria das amostras as perdas dos teores de zinco foi inferior a $25 \%$, as amostras de aves do tipo coxa de frango apresentaram perdas em média de $35 \%$.

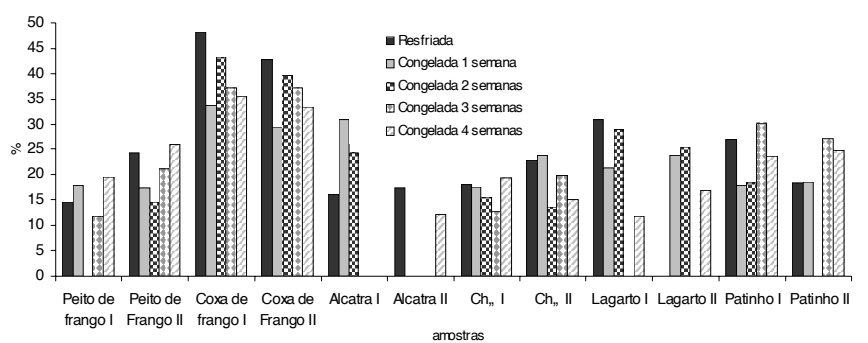

FIGURA 2. Teor \% de zinco perdido durante processo térmico de amostras de carnes resfriadas e congeladas até 4 semanas 
Comparando as perdas dos teores de cobre e zinco nas amostras estudadas verifica-se que para a maioria delas houve maior perda do zinco. Interessante observar que as amostras de carne bovina do tipo patinho apresentaram comportamento similar com os dois metais analisados.

É possivel observar que algumas amostras como peito de frango, alcatra, lagarto e patinho, em alguns períodos de congelamento não apresentaram perdas significativas do zinco durante o processamento térmico.

O processo de congelamento que ocorreu nas amostras é caracterizado pelo congelamento do tipo lento que leva a formação de cristais de gelo grandes nos espaços intracelulares e no interior das células. Estes cristais grandes podem levar ao rompimento das células e de tecidos o que pode acarretar no aprisionamento de sólidos no interior dos mesmos. Com o processo de descongelamento ocorrem perdas através do gotejamento da água formada e conseqüentemente dos sólidos ali dissolvidos, por não ocorrer reabsorção total do suco da carne [12, 13]. Verifica-se que houve uma influência no tipo do tecido das amostras de carnes estudadas, pois as perdas foram diferenciadas mesmo havendo o mesmo processo de conservação e cocção. Mesmo com perdas no processamento térmico, e com a conservação em temperatura de congelamento durante o período de 4 semanas, o teor de cobre na maioria das amostras estudadas foi superior a $0,025 \mathrm{mg} \%$. O teor de zinco, foi superior a $0,3 \mathrm{mg} \%$ para as amostras de carnes de aves e $0,6 \mathrm{mg} \%$ para as amostras de carnes bovinas. Considerando que as DRIs (Dietary Reference Intakes) para o cobre é de 1,0 a $1,6 \mathrm{mg} /$ dia, tolerável $10 \mathrm{mg} /$ dia e para o zinco de 9 a $14 \mathrm{mg} /$ dia, tolerável 40mg/ dia para adultos [7, 9]; o consumo diário de $200 \mathrm{~g}$ de carnes dos tipos estudados fornecerá no mínimo 5\% dos teores recomendados de cobre e zinco. Os resultados ainda demonstram que o processo de congelamento interfere nos teores destes metais, promovendo perdas nutricionais, o que sugere utilizar carnes resfriadas ou congeladas por períodos de no máximo 1 semana.

Observa-se ainda que o teor de zinco na maioria das amostras resfriadas e processadas termicamente de carnes bovinas, sem passar por processo de congelamento, é superior a $3 \mathrm{mg} \%$, o que corresponde a $20 \%$ em média da recomendação diária deste metal, caracterizando uma boa fonte deste elemento.

\section{4 - CONCLUSÕES}

Considerando que as amostras de carnes analisadas podem ser consideradas boas fontes de cobre e zinco, torna-se importante avaliar o método de conservação destas amostras para que haja menor perda nutricional em relação aos metais cobre e zinco. O es- tudo mostra que o processo de congelamento leva a perdas consideráveis destes metais sugerindo que este tipo de alimento deve ser conservado em refrigeração ou optando por congelamento, utilizar o tempo máximo de 1 semana.

\section{5 - REFERÊNCIAS BIBLIOGRÁFICAS}

[1] BARAN, J.E. Química Bioinorgânica - Mc Graw - Hill/ Interamericana de Espana, SA - Madrid, 1995.

[2] BELITZ, H-D; GROSCH, W. Química de los Alimentos, Zaragoza: Acribia SA, Espanha, 1988.

[3] BEN, A.M. Effect of Freezing and Microbial Growth on Myoglobin Derivates of Beef. Food Chemistry, v. 147, n. 10 , p. 4093, 1999.

[4] Cozzolino, S.M.F. Biodisponibilidade de Minerais. Revista Nutrição, Campinas, p. 87-98, jul-dez, 1997.

[5] EVAngelista, J. Tecnologia de Alimentos, $2^{\text {a }}$ ed., São Paulo: Editora Atheneu, 2000.

[6] FIBIANE, M.A. The Principles of Bio-inorganic Chemistry - The Chemical Society Monographs For Teachers n 31- The Chemical Society, London 1977.

[7] FRANCO, G. Tabela de Composição Química de Alimentos. Editora: Atheneu, Rio de Janeiro, 1999.

[8] MAHAN, L.K. Krause: Alimentos, Nutrição \& Dietoterapia, São Paulo: Rocca, 9a ed., 1998.

[9] OLIVEIRA, J.M. A Teoria Ortomolecular em Medicina Clínica. Ed. Arte Zen 2000 prod. gráficos e visuais Ltda, Rio de Janeiro, 1995.

[10] ORGANIZAÇÃO MUNDIAL DE SAÚdE. Elementos Traço na Nutrição e Saúde. Roca, São Paulo, 1998.

[11] OSLON, J.A. Modern Nutrition in Health and Disease, $8^{a}$ ed., Lea \& Febiger, USA, 1994.

[12] OSTROUMOV, V.; HOOVER, R.; OSTROUMOVA, N.; VLIETE-LANOE, B.; SIEGERT, C.; SOROVIKOV, V. Redristribution of Soluble Components During Ice Segregation in Freezing Ground. Cold Regions Science and Tecnology, v. 32, n. 2, p. 175, 2001.

[13] SANZ, P.D.; OTERO, L.; DE ELVIRA, C.; CARRASCO, J.A. Freezing Rate Simulation as an Aid to Reducing Crystalization Demage in Foods. Meat Science, v. 52, n. 3, p. 275, 1999.

[14] SOLOMON, R.E. Production of Red Meat Should be Curbed in Order to Conserve Natural Resources. Journal of the American Dietetic Association, v. 97, n. 11 , p. 1249, 1997.

[15] SOLOMONS, N.W. Competitive Interation of Iron and Zinc in the Diet: Consequences for Human Nutrition. Journal of Nutrition, v. 116, n. 6, p. 927-934, 1986.

[16] TURNLUND, J.R. Copper Nutriture, Biovailability and the Influence of Dietery Factors. Journal of the American Dietetic Association, v. 88, n. 3, p. 303310, 1988.

[17] WAPNIR, R.A.; STIEL, L. Intestinal Absorption of Copper: Effect of Sodium Proceeding of the Society for Experimental Biology and Medicine, v. 185, n. 3, p. 277$282,1987$.

[18] WAITZBERG, D.L. Nutrição Oral, Enteral e Parenteral na Prática Clínica. São Paulo: Atheneu, 2000. 